\title{
Emerging regional climate change signals for Europe under varying large-scale circulation conditions
}

\author{
Erik Kjellström ${ }^{1,2, *}$, Peter Thejll ${ }^{3}$, Markku Rummukainen ${ }^{1,4}$, Jens H. Christensen ${ }^{3}$, \\ Fredrik Boberg ${ }^{3}$, Ole B. Christensen ${ }^{3}$, Cathrine Fox Maule ${ }^{3}$ \\ ${ }^{1}$ Swedish Meteorological and Hydrological Institute, 60176 Norrköping, Sweden \\ ${ }^{2}$ Department of Meteorology, Stockholm University, 10691 Stockholm, Sweden \\ ${ }^{3}$ Danish Meteorological Institute, 2100 Copenhagen, Denmark \\ ${ }^{4}$ Centre for Environmental and Climate Research, Lund University, 22362 Lund, Sweden
}

\begin{abstract}
A large ensemble of regional climate model projections was investigated regarding if and when they show an emergence of significant climate change signals in seasonal temperature and precipitation within Europe. The influence of the North Atlantic Oscillation (NAO), as simulated in the projections, was investigated. In most parts of Europe, the projections indicate robust emergence of temperature change in the first 2 decades of the 21st century, typically earlier for summer than for winter. For precipitation changes, signals generally emerge much later than for temperature. For Europe as a whole, the precipitation signals tend to emerge some 40 to $60 \mathrm{yr}$ later than the temperature signals. In some sub-regions, robust signals for precipitation are not found within the studied period, i.e. until 2100. Some sub-regions, notably the Mediterranean area and Scandinavia, show different behaviour in some aspects compared to the ensemble-based results as a whole. NAO has some influence on the temperature change signals, which emerge earlier in winter for some models and regions if NAO is accounted for. For summer temperatures, the influence of NAO is less evident. Similarly, for precipitation, accounting for NAO leads to an earlier emergence in some regions and models. Here, we find an impact for both summer and winter.
\end{abstract}

KEY WORDS: Climate change $\cdot$ Emerging trends $\cdot$ Europe $\cdot$ Regional climate models $\cdot$ NAO

\section{INTRODUCTION}

Climate projections for the 21st century show successive and substantial changes in regional climate aspects related to global warming (e.g. Christensen et al. 2007). Large-scale patterns such as a larger warming over the continents than over the oceans, maximum warming in the Arctic region and a general amplification of the hydrological cycle are common to all projections. However, there are also important differences. On the global scale, differences between projections are related to uncertainties in the climate forcing itself (emission pathways), the climate sensitivity and, especially for the early part of the century, internal variability of the climate system (Hawkins \& Sutton 2009). The latter is even more of an issue on regional scales than on the global scale (Hegerl \& Zwiers 2011) and thus is an important source of uncertainty in understanding regionalscale climate change signals. These uncertainties warrant careful consideration with ensemble approaches that enable characterization of both the common features in the projections and the uncertainties. This includes an improved understanding of the role of the large-scale internal variability as it may severely mask the externally driven climate 


\section{DATA AND METHODS}

\subsection{Regional climate model data}

We used monthly mean temperature, precipitation and mean sea level pressure (MSLP) fields from 21 RCM simulations from the ENSEMBLES database at DMI (ENSEMBLES 2012) (Table 1). We based most of our analysis on the 15 simulations that cover the full 1961-2099 period and use the remaining 6 ending in 2050 to discuss the uncertainty in the results. The ENSEMBLES simulations were made with 11 different RCMs. Some of these were run with different set-ups. For instance, the Hadley Centre RCM, HadRM3, was used in 3 different configurations with different parameter settings from a perturbed physics ensemble (Collins et al. 2011). The RCMs' boundary conditions were derived from 8 different GCMs. The anthropogenic climate forcing followed the A1B emission scenario (Nakićenović \& Swart 2000). In some RCMs, direct and indirect effects on the climate from sulphate aerosols were included in addition to the effect of increased amounts of greenhouse gases (GHG), while in others, only the GHG increases were accounted for. available prior to 1963). We calculated when the temperature and precipitation deviated from the 1961-1990 reference period for winter (December to February, DJF) and summer (June to August, JJA) in each region. These deviations were expressed as a probability given the standard deviations of 2 samples; one from the reference period covering $30 \mathrm{yr}$ and the other from a sliding window of length of $30 \mathrm{yr}$. The probability that these 2 samples were drawn from the same population was then calculated using Student's means test. If the hypothesis that they were drawn from the same population could be rejected at the $1 \%$ level (a $1 \%$ chance that the rejection was due to a chance occurrence), then the centre year of the sample interval for that model (cf. Fig. 2) was assigned as the time when the climate change signal emerged. Temporal autocorrelation was not accounted for in the calculation of the $t$-test statistics. This means that the estimated climate change signal may emerge too early. However, the autocorrelation for seasonal mean temperature and precipitation in the RCM data is relatively small (data not shown), implying that the inferred error is small. Also, we note that the autocorrelation is of similar size for temperature and precipitation, implying that the time of emergence (ToE) can be compared between

\subsection{Observational data}

In addition to the RCM data, we used gridded observational temperature and precipitation data from EOBS5.0 (Haylock et al. 2008) for comparing spatial patterns and temporal trends. The E-OBS data are available at the same rotated $25 \times 25 \mathrm{~km}$ grid that is used by most of the ENSEMBLES RCMs. NAO was characterized with a station-based seasonal mean NAO index (NAOI) (NAO 2012).

\subsection{Methods}

Temperature and precipitation data were averaged for the 9 regions shown in Fig. 1 for both the RCMs and the E-OBS data. Anomalies were then calculated by subtracting the average in the period 1961-1990 (except for Model 7, for which 19631990 was used as no data were

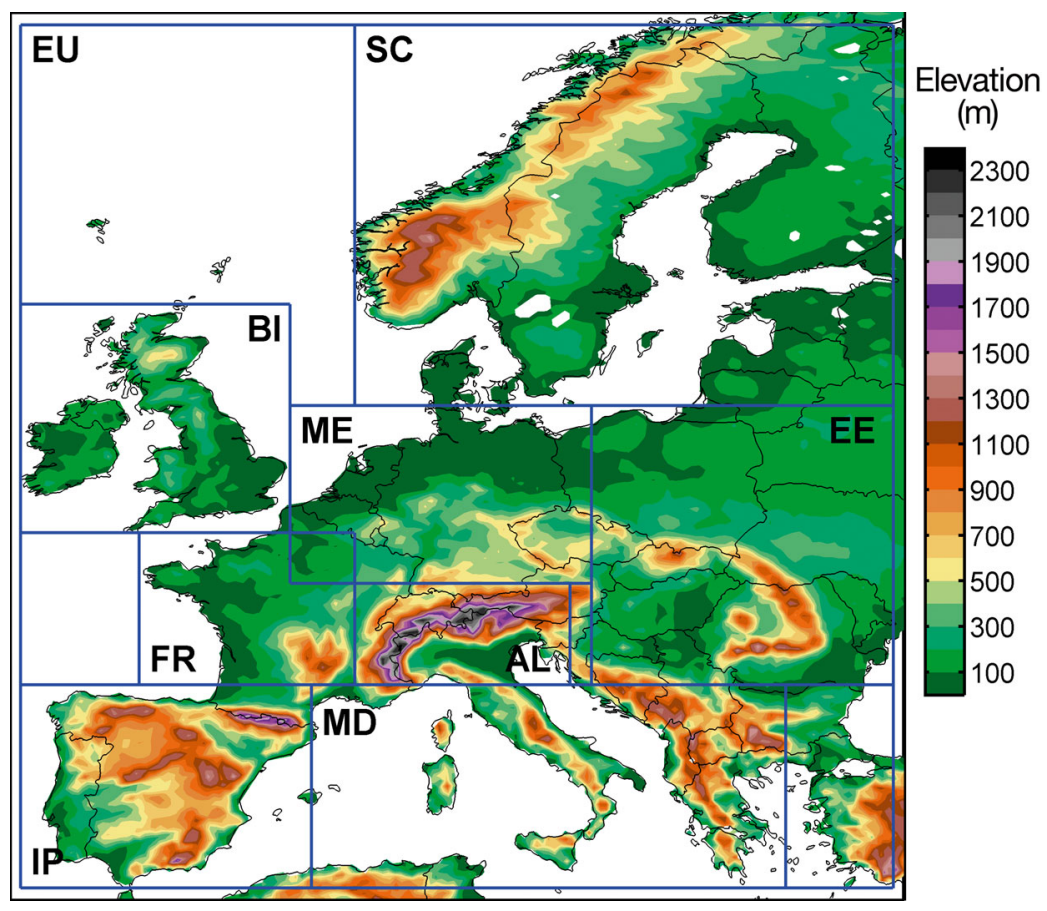

Fig. 1. Areas used in the analysis. The overall European region (EU) encompasses the entire domain shown in the figure. The colours represent the orography as prescribed in the HIRHAM5 model at DMI. See Table 2 for abbreviations 
the 2 variables. The test was applied for all RCMs against the 1961-1990 reference period drawn from the respective model and also for the E-OBS data against the E-OBS 1961-1990 period.

As the westward extension in the ENSEMBLES RCMs precludes the use of a standard EOF-based analysis of the NAO index (NAOI), we used the station-based formulation by Hurrell (1995). This is the difference between the normalized MSLP anomalies in Stykkishólmur in Iceland and in Lisbon in Portugal. The anomaly for an individual 3 mo season is normalized by the long-term standard deviation $\left(\sigma_{\text {MSLP }}\right)$ according to the following relation:

$\mathrm{NAOI}_{i}=\left(\frac{\mathrm{MSLP}_{i}-\overline{\mathrm{MSLP}}}{\sigma_{\mathrm{MSLP}}}\right)_{\text {Lisbon }}-\left(\frac{\mathrm{MSLP}_{i}-\overline{\mathrm{MSLP}}}{\sigma_{\mathrm{MSLP}}}\right)_{\text {Stykkisholmur }}$

where the overbar denotes an average over all of the individual years (i) in the period.

Here, NAOI characterises the large-scale circulation in the GCMs that provided the RCMs with boundary conditions. Specifically, we used the MSLP from 8 of the RCM simulations that had been forced by different GCMs (Table 1). The NAOI time series were then also used for the other RCMs that had been forced with the same GCMs, as appropriate.

Temporal correlations between the NAOI and seasonal mean temperature and precipitation were calculated by the ordinary Pearson product-moment procedure for each grid point. Statistical significance of the correlations was established by Monte Carlo testing using the 'randomized phases' method wherein surrogate data are generated with the same auto-correlation spectrum as the original data (e.g. Ebisuzaki 1997). Significance levels were estimated from the histogram of correlations generated from repeated tests on surrogate data. We arbitrarily chose a cutoff at the $95 \%$ significance level, estimated from Monte Carlo trials on surrogate data generated by the 'scrambled phases' method (Thejll 2001).

Finally, we removed the influence from the NAO and repeated our analysis of when significant changes occur. The influence of the NAO was determined by linear regression in which a statistical model was first fitted to the relation between the NAOI and the variable in question using the following equation:

$$
X=a+b \times \mathrm{NAOI}+\varepsilon
$$

where $X$ is either temperature or precipitation, $a$ and $b$ are regression coefficients, and $\varepsilon$ is the noise. The residuals were then used in the repeated analysis after removing the linear trend $(b \times \mathrm{NAOI})$.

\section{TEMPERATURE AND PRECIPITATION SIGNALS}

Time series for temperature and precipitation changes in the overall European region ('EU'; Fig. 1) are shown in Fig. 2. To reduce the number of lines, only the 2 models for which a statistically significant change emerges the earliest and the 2 for which it emerges the latest in the 21st century are plotted. The RCM results are characterized by increasing temperatures, while for precipitation, there is an increase in winter and a summertime decrease in 3 out of 4 of the models shown in Fig. 2. The 'early' models show emergence of changes in temperature as early as the E-OBS data does. The 'late' models show a much later ToE. For winter, the simulated interannual variability in 1961-1990 is similar in the 2 'early' RCMs and also in line with that in the E-OBS data both in terms of the geographical distribution and also amplitude (data not shown). For both of the 'late' models, the inter-annual variability is smaller than in E-OBS and the 2 'early' RCMs. This relation between strong inter-annual variability in the 'early' models and weak in the 'late' ones implies that it is the amplitude of the change as seen in Fig. 2 that is responsible for the ToE and that inter-annual variability plays a less important role. Also, in summer, the amplitude of the change appears to be more important for discriminating between 'early' and 'late' models as all 4 in this case show an inter-annual variability in 1961-1990 that is similar to each other and also close to that in E-OBS (data not shown). For precipitation, there is no significant change in the EOBS data on the pan-European level, which fits well with the tendency of precipitation trends to differ among different areas (e.g. van Haren et al. 2012).

The spatial distribution of the RCM simulated climate change signal for Europe is shown in Fig. 3 using lower, median and upper percentiles of the climate change between 2021-2050 and 1961-1990 in the 21-member RCM ensemble for seasonal mean temperature and precipitation. These results align well with those from previous studies (e.g. Christensen \& Christensen 2007, Kjellström et al. 2011, Déqué et al. 2012). The temperature increases are generally larger over land than over the Atlantic, with the largest increases in the northeast during winter and in the south during summer. In Southern Europe, where present day precipitation amounts are already low, precipitation decreases, especially in summer. On a more detailed level, another typical RCM scenario feature shows up as a relatively large increase in summertime precipitation over the Baltic 

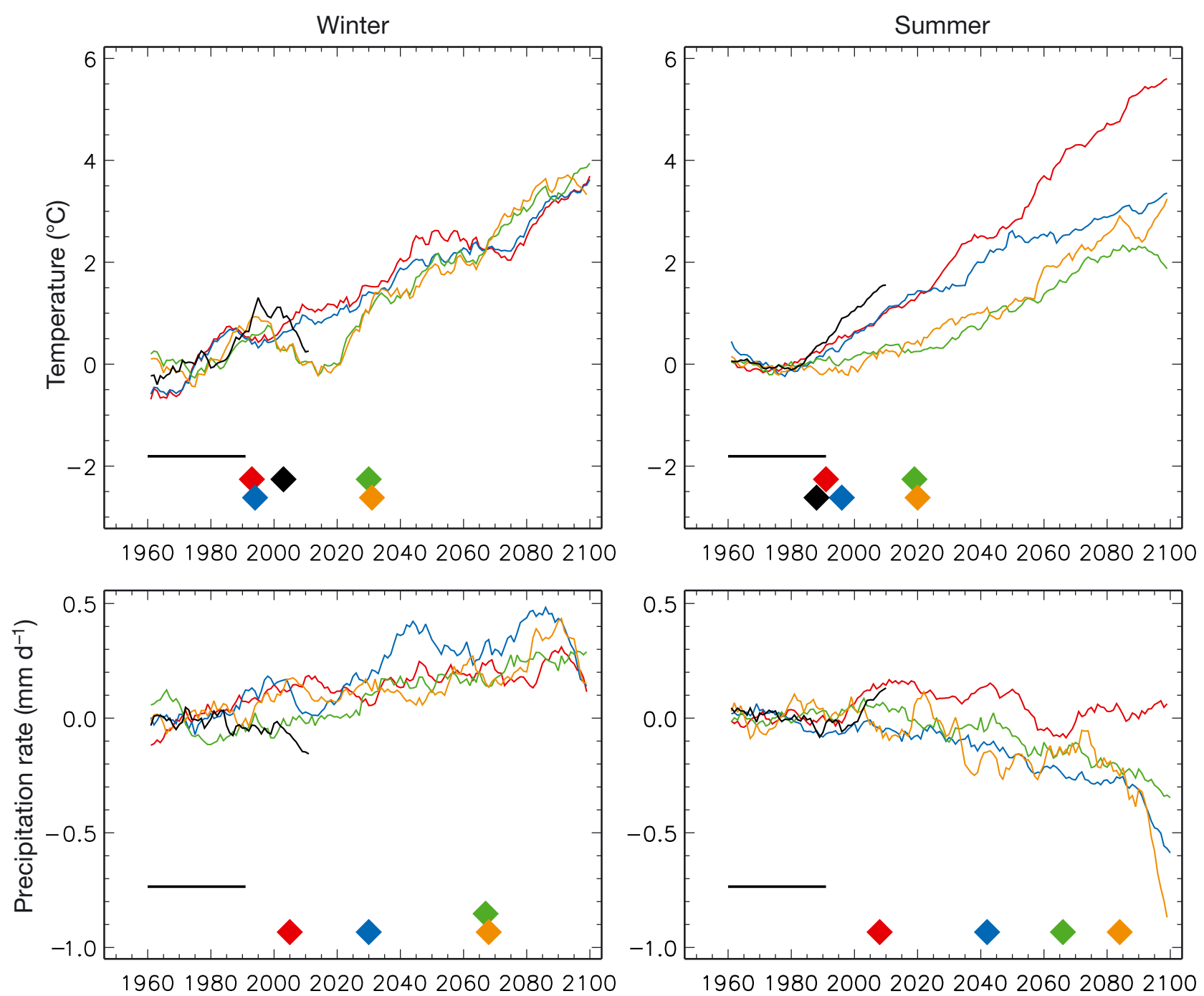

Fig. 2. Temporal evolution of temperature (top) and precipitation anomalies (bottom) for winter (left) and summer (right) for the EU region (see Fig. 1). The diamonds show the first year of change (YC) for 4 models and the E-OBS data. The 4 RCMs shown were the 2 first and 2 last models to show such a YC inside the data interval. For E-OBS, diamonds are only shown for temperature as a YC is not detectable for precipitation. RCM and E-OBS are compared to the reference period (1961-1990, indicated by the black horizontal line) for the respective data sets. E-OBS is always shown in black, while the RCMs are colour coded red, blue, green, and orange for RCMs 3, 2, 8 and 4 (cf. Table 1) for winter temperature; 18, 10, 5 and 4 (summer temperature); 5, 1, 18 and 10 (winter precipitation); and 1, 15, 3 and 10 (summer precipitation), respectively. The data were smoothed with a 30 yr window, starting from 1991

Sea, likely connected to high sea surface temperatures in the underlying GCMs (cf. Kjellström \& Ruosteenoja 2007). Although the large-scale patterns are very similar across the models, there is a large spread in the actual numbers, especially for precipitation. In some areas, there is a lack of agreement about the sign of projected precipitation change, which implies small projected changes that do not reach outside the baseline variability limits. It could also be that different models do simulate statistically significant changes but of opposite sign.
Fig. 4 shows the same change as in Fig. 3, but now divided by the inter-annual variability in the 19611990 period. This gives an indication of where the signal-to-noise ratio is high and consequently where an early emergence of a climate change signal can be expected. For temperature, the signal-to-noise ratio is generally largest in the Mediterranean area in both summer and winter. The ratio is lower in Northern Europe due to a relatively weak change in summer (Fig. 3). This is also the case in winter for the British Isles, while it is the large inter-annual vari- 

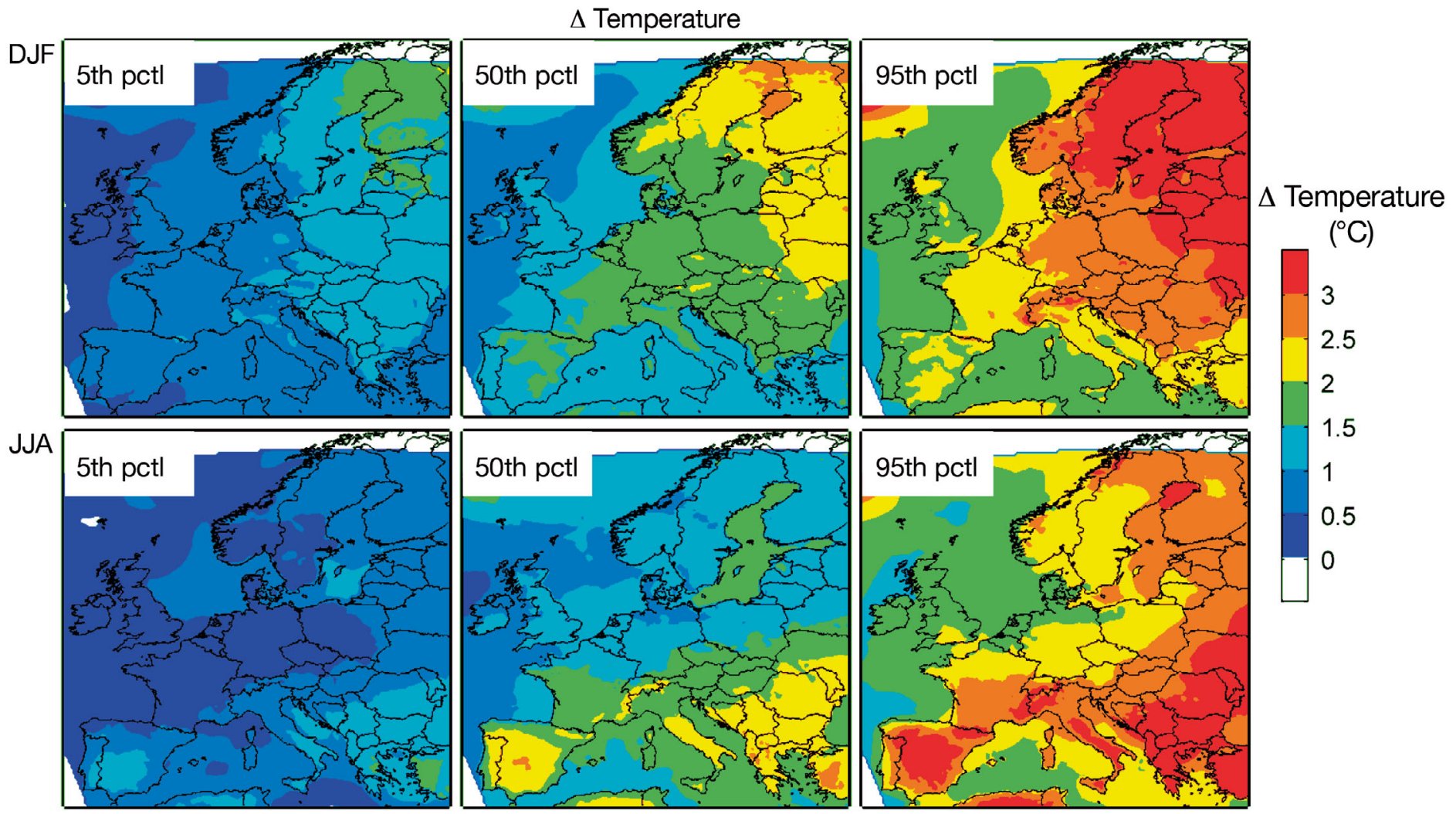

\section{$\Delta$ Precipitation}
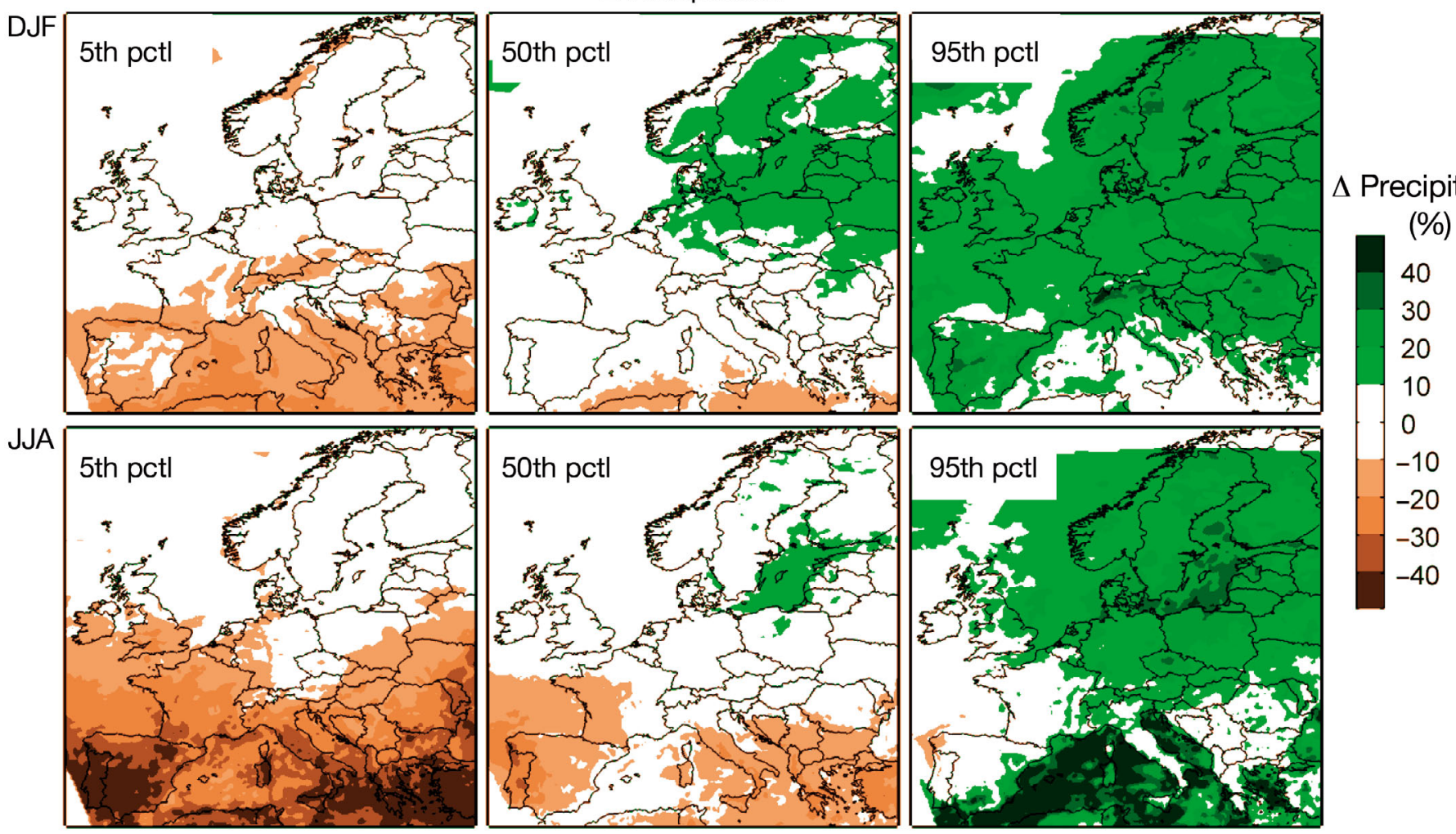

Fig. 3. Seasonal change in temperature and precipitation for the 21 RCMs for the period 2021-2050 relative to 1961-1990. The 3 percentiles are calculated separately for each grid point by use of the nearest rank, i.e. models ranking 2nd, 11th and 20th 


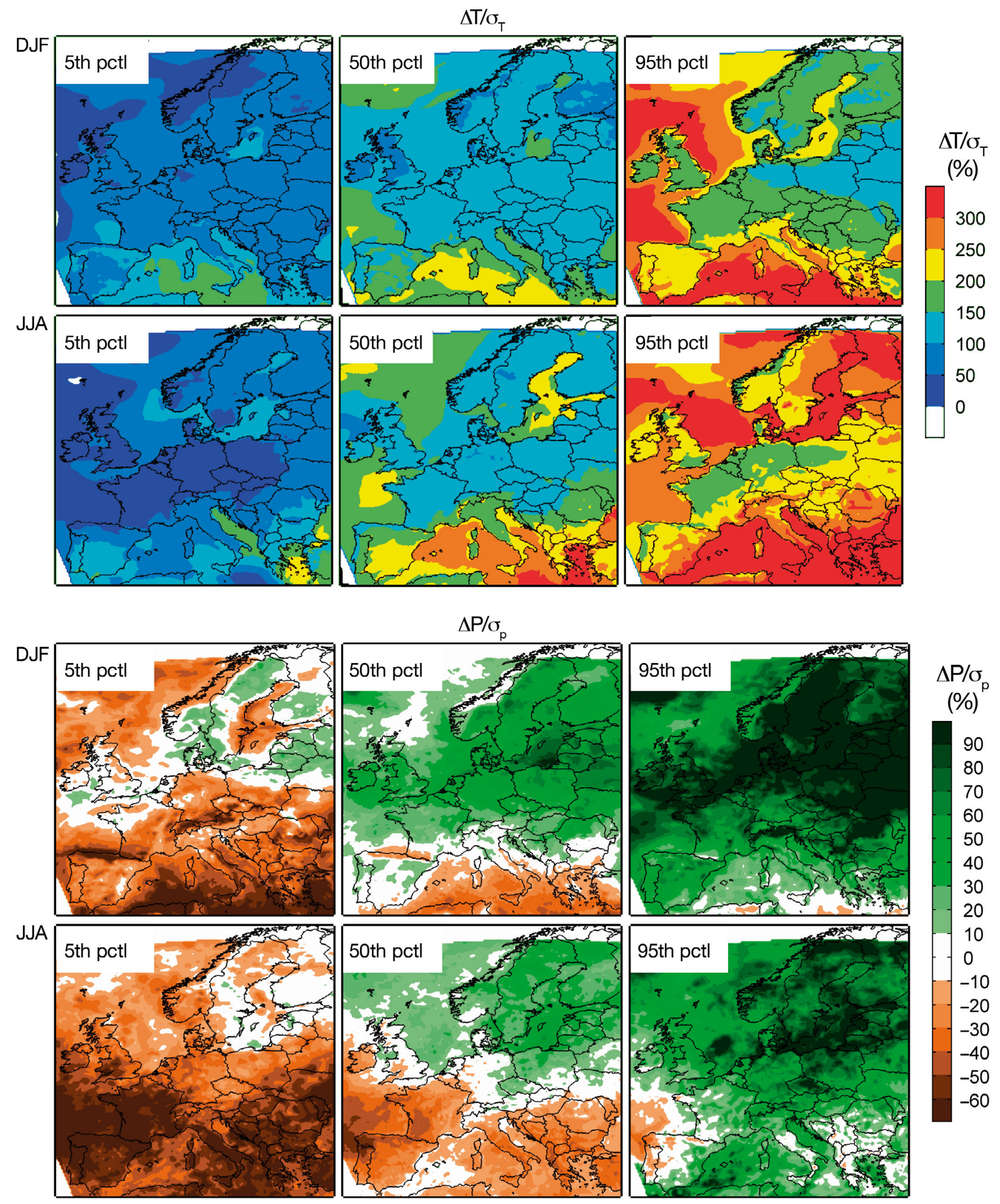

Fig. 4. Seasonal change for the 21 RCMs for the period 2021-2050 relative to 1961-1990 divided by the inter-annual variability in 1961-1990. See Fig. 3 for further detail 

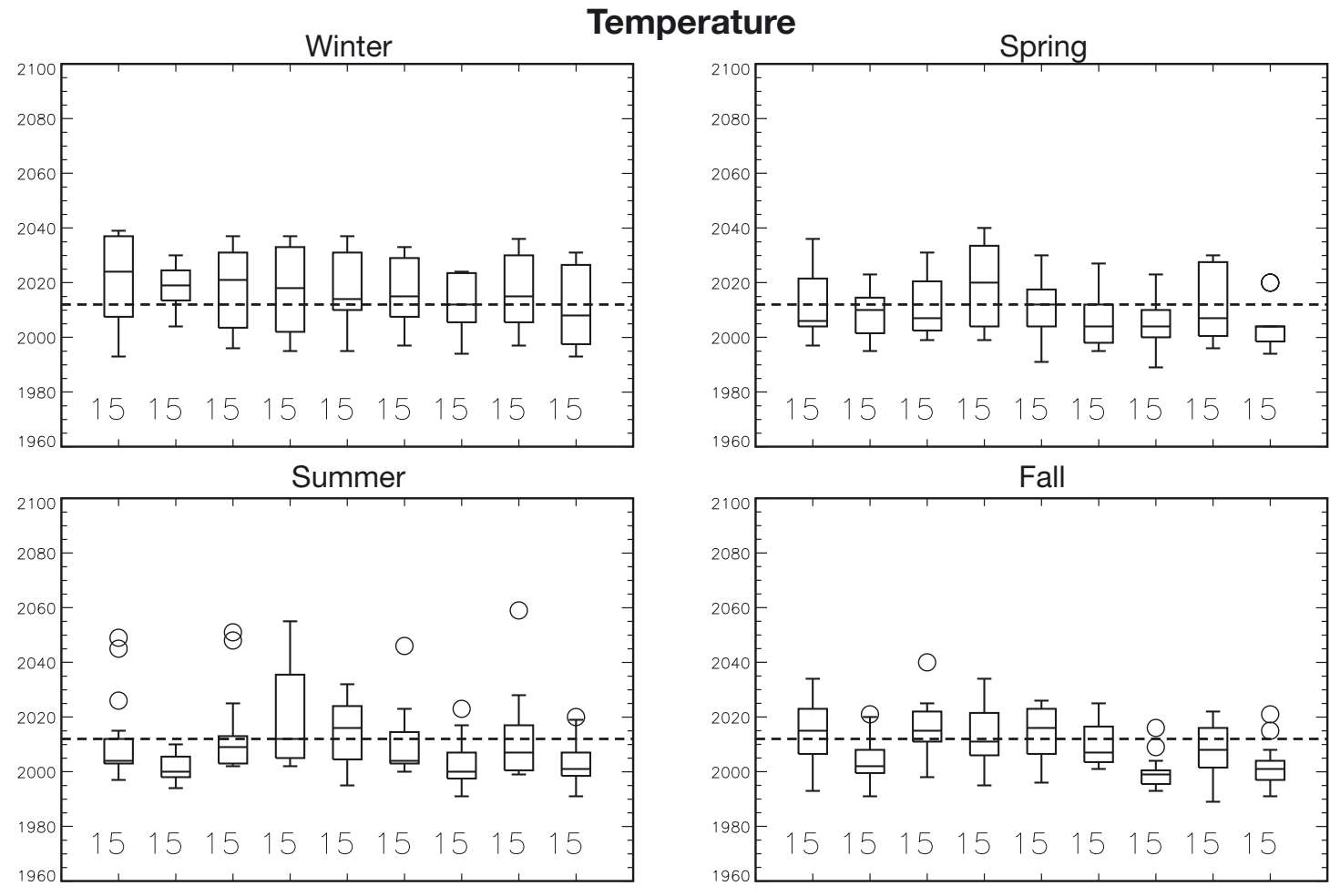

BI IP FR ME SC AL MD EE EU

BI IP FR ME SC AL MD EE EU

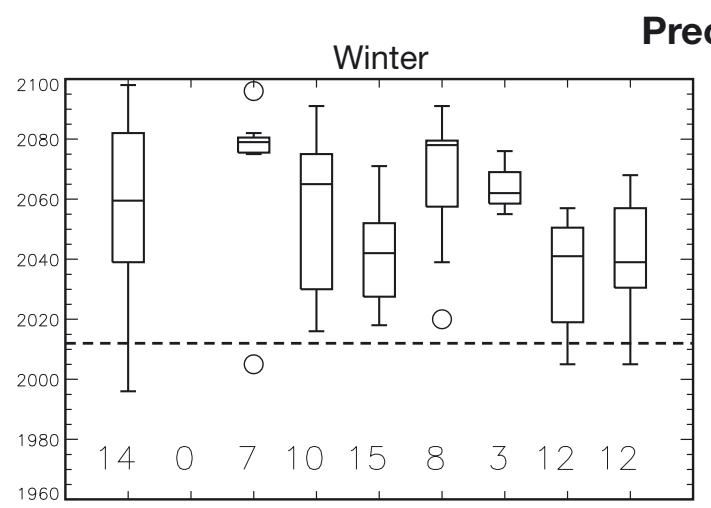

Summer

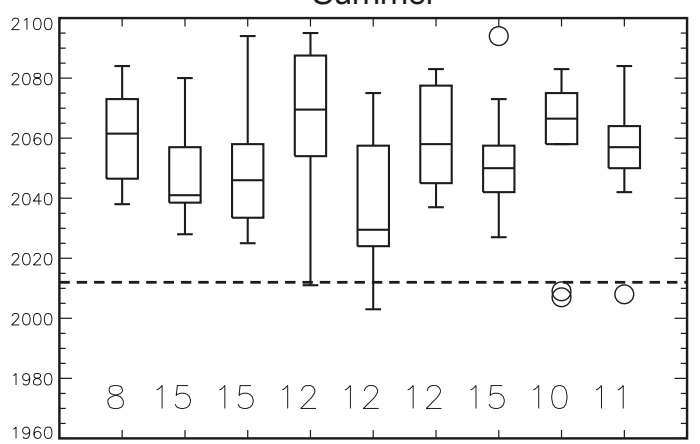

BI IP FR ME SC AL MD EE EU

Spring

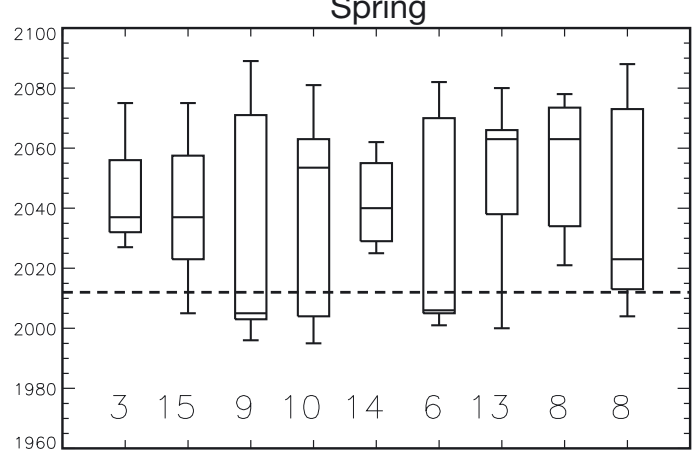

Fall

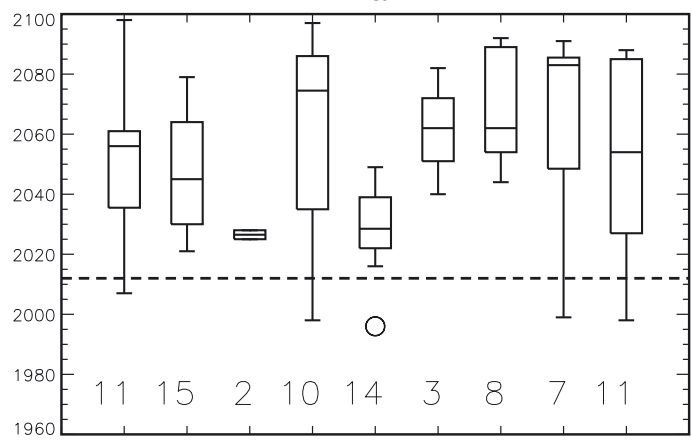

BI IP FR ME SC AL MD EE EU

Fig. 5. Bar-whisker plots of the years of first significant change in temperature for all regions and seasons. The box encloses the interquartile range (IQR); the whiskers extend from the median to 1.5-fold the 1st or the 3rd quartile or to the maximum or minimum of the data if any of these lie within this interval. If data lie beyond this range, they are considered outliers and marked with a circle. The year 2012 is shown with a dashed line. The numbers presented for each region denote how many models reached a significant change before 2100 and thereby are included in the box-whisker plots. See Table 2 for abbreviations 
ability (data not shown) that is responsible for the relatively weak signal-to-noise ratio in Scandinavia, which otherwise shows a strong change (Fig. 3). For precipitation, there are local maxima in the signal-tonoise ratio in both Southern Europe (with a negative sign as the trend is negative) and Northern Europe. The signal-to-noise ratio is generally lower for precipitation than for temperature.

Fig. 5 and Table 2 show the timing of when statistically significant changes appear in the 15 -member RCM ensemble that goes to 2100 for individual regions and seasons. In all regions as well as in the pan-European region, there is a robust indication of temperature change in the near future. For instance, changes are obvious in winter temperatures in the first 2 decades of the 21st century in all regions apart from the British Isles, where the signal-to-noise ratio

Table 2. Median years of change (YC) in temperature and precipitation for winter (DJF) and summer (JJA). The first column for each variable represents original model data. The second represent the $\mathrm{YC}$ when the influence of the NAO has been removed. 21++ indicates that YC occurs after 2100 in more than half of the models. Italics indicate that between half and all but one model reach YC before 2100

\begin{tabular}{|c|c|c|c|c|}
\hline \multirow[t]{2}{*}{ Season } & \multicolumn{2}{|c|}{ Temperature } & \multicolumn{2}{|c|}{ Precipitation } \\
\hline & Original & $\begin{array}{l}\text { Without } \\
\text { NAO }\end{array}$ & Original & $\begin{array}{c}\text { Without } \\
\text { NAO }\end{array}$ \\
\hline \multicolumn{5}{|c|}{ BI (British Isles) } \\
\hline DJF & 2024 & 2019 & 2067 & 2050 \\
\hline JJA & 2004 & 2007 & 2084 & 2084 \\
\hline \multicolumn{5}{|c|}{ IP (Iberian Peninsula) } \\
\hline DJF & 2019 & 2016 & $21++$ & $21++$ \\
\hline JJA & 2000 & 2000 & 2041 & 2039 \\
\hline \multicolumn{5}{|c|}{ FR (France) } \\
\hline DJF & 2021 & 2021 & $21++$ & $21++$ \\
\hline JJA & 2009 & 2013 & 2046 & 2046 \\
\hline \multicolumn{5}{|c|}{ ME (Mid-Europe) } \\
\hline DJF & 2018 & 2014 & 2075 & 2084 \\
\hline JJA & 2012 & 2012 & 2080 & 2080 \\
\hline \multicolumn{5}{|c|}{ SC (Scandinavia) } \\
\hline DJF & 2014 & 2014 & 2042 & 2039 \\
\hline JJA & 2016 & 2016 & 2037 & 2037 \\
\hline \multicolumn{5}{|c|}{ AL (Alps) } \\
\hline DJF & 2015 & 2014 & 2091 & 2081 \\
\hline JJA & 2004 & 2004 & 2066 & 2063 \\
\hline \multicolumn{5}{|c|}{ MD (Mediterranean) } \\
\hline DJF & 2012 & 2002 & $21++$ & 2059 \\
\hline JJA & 2000 & 2002 & 2050 & 2050 \\
\hline \multicolumn{5}{|c|}{ EE (Eastern Europe) } \\
\hline DJF & 2015 & 2018 & 2049 & 2041 \\
\hline JJA & 2007 & 2007 & 2075 & 2075 \\
\hline \multicolumn{5}{|c|}{ EU (all of Europe) } \\
\hline DJF & 2008 & 2004 & 2050 & 2040 \\
\hline JJA & 2001 & 2001 & 2063 & 2063 \\
\hline
\end{tabular}

is low (Fig. 4). In the latter region, the ensemble median indicates that a statistically significant change does not emerge until around the mid-2020s. As an example of early emergence, results for the Iberian Peninsula and the Mediterranean region show summer change already around 2000, which is consistent with the high signal-to-noise ratio (Fig. 4). A comparison of the seasons shows that the projected change generally occurs earlier in summer than in winter. Also, spring and fall show earlier emergence than winter and a comparatively small spread among the simulations (Fig. 5). In all seasons, the change generally occurs earlier when considering the European region as a whole than in any of the sub-regions. This is likely due to the larger number of time series being combined for the larger region, which lowers the variance in the average series and, in turn, allows earlier detection. Exceptions here are the Mediterranean region and the Iberian Peninsula, with equally early emergence as the overall European region in summer and fall. This is due to the strong signal-to-noise ratio in this region (cf. Fig. 4 for summer conditions).

In the case of precipitation, the change generally emerges much later than for temperature and in many cases does not appear within the time window studied here, i.e. until 2099. For instance, there is not one single model that shows a statistically significant change for the Iberian Peninsula in winter over the whole period (Fig. 5). In case less than half of the models show a statistically significant change before 2099, we therefore denote the median year in Table 2 with '21++'. From Table 2, it is clear that this situation applies for large parts of Southern Europe in winter. It is only in Scandinavia in winter and in Southern Europe in summer that all models show a statistically significant change before 2100. On a pan-European scale and for the remaining regions, more than half but not all of the models show a significant change before 2100 in all seasons. In these cases, the median in Table 2 is calculated from the actual year of change in the models showing it before 2099 and a sequence of $\mathrm{YC}=2100$ for those not showing it. We note that this estimate of an emergence is earlier than what would have been the case if the simulations had continued after 2100 (possibly there may not be a significant change even after that time). Finally, we observe that the spread between the models is larger for precipitation compared to that for temperature. For those models showing a change, precipitation change lags that in temperature, often with several decades for most individual regions and seasons. 

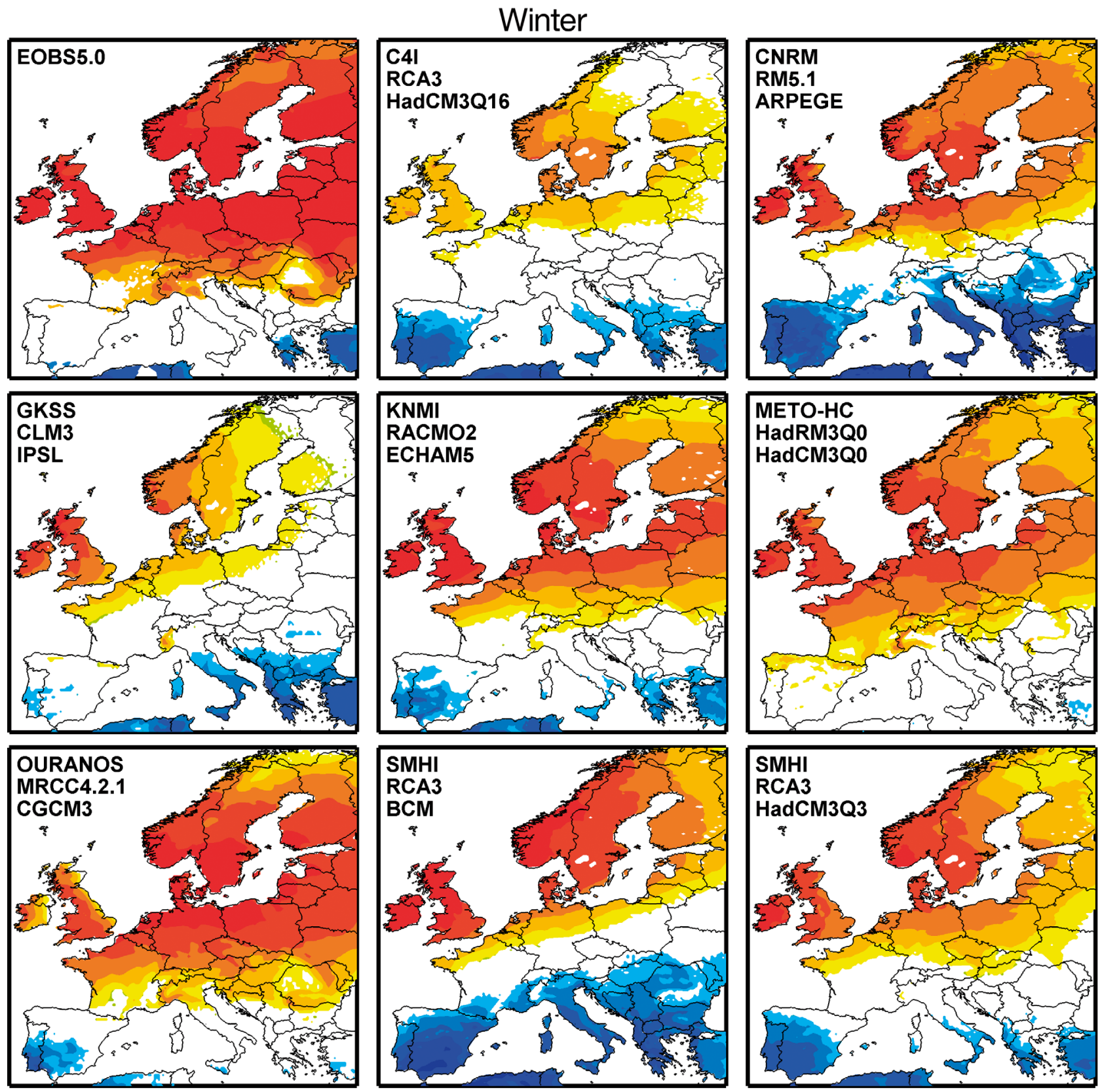

$-0.6$

$\begin{array}{llllll}-0.4 & -0.2 & 0 & 0.2 & 0.4 & 0.6\end{array}$

\section{Correlation}

Fig. 6. (Continued on next page.) Temporal correlation between seasonal mean North Atlantic Oscillation index (NAOI) and temperature for 1961-2050. This page: winter (DJF), next page: summer (JJA). The first panel in each set shows the correlation between observed temperatures (E-OBS) and the NAOI. In the other panels, the model NAOI is correlated with the model temperature. Only correlations above a $95 \%$ significance level are shown

\section{INFLUENCE OF THE NAO}

The NAO exerts major influence on the interseasonal and inter-annual temperature and precipitation variability in Western Europe (e.g. Hurrell 1995, Pinto \& Raible 2012). Unforced NAO variations can both add to and subtract from forced regional climate trends. GCM results indicate that the NAO will generally be more positive with the overall global warming, but the magnitude of the changes is uncertain (Meehl et al. 2007). We remove the NAO in the statistical sense from the RCM data and see whether this 

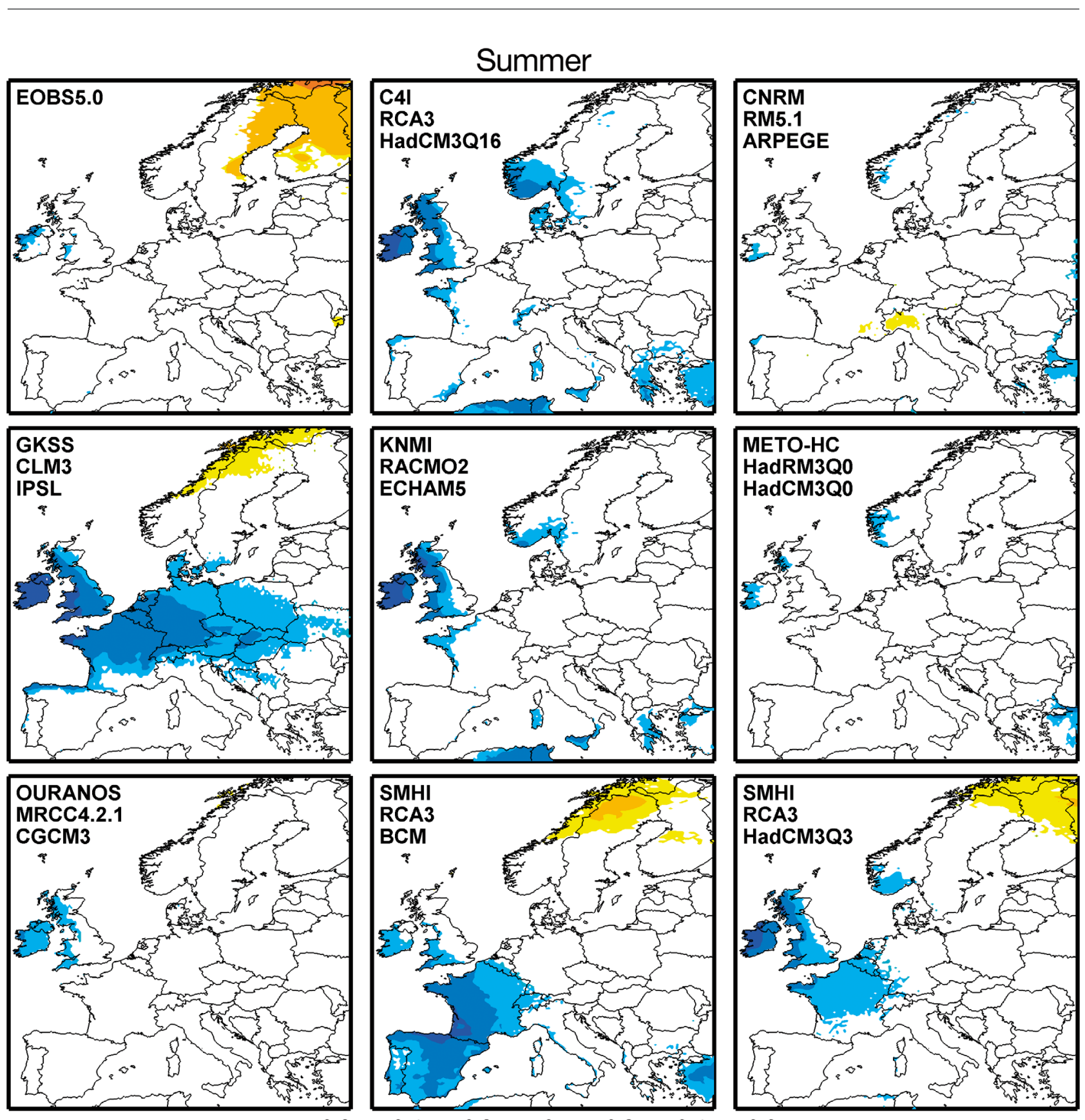

$-0.6$

$\begin{array}{ll}-0.4 & -0.2\end{array}$

\section{Correlation}

Fig. 6. (continued)

affects the emergence of the change signals in temperature and precipitation. Figs. $6 \& 7$ present ordinary Pearson correlations between the NAOI and seasonal mean temperature and precipitation. Calculations are done for the period 1961-2050. Areas of low correlation (and significance) are masked out. The results are much as expected. Milder and wetter wintertime conditions in Northern and Western Europe are linked to the positive phase of the NAO, as are colder and drier conditions in the southwest and the Mediterranean region. The connections are more marked in winter when the influence of the largescale circulation is more dominant than in summer. In summer, there is an indication of more precipitation in the Scandinavian mountains and warmer conditions in northernmost Scandinavia in situations with high NAOI both in the E-OBS data and in many of the RCMs. There is also a negative correlation for tem- 


\section{Winter}
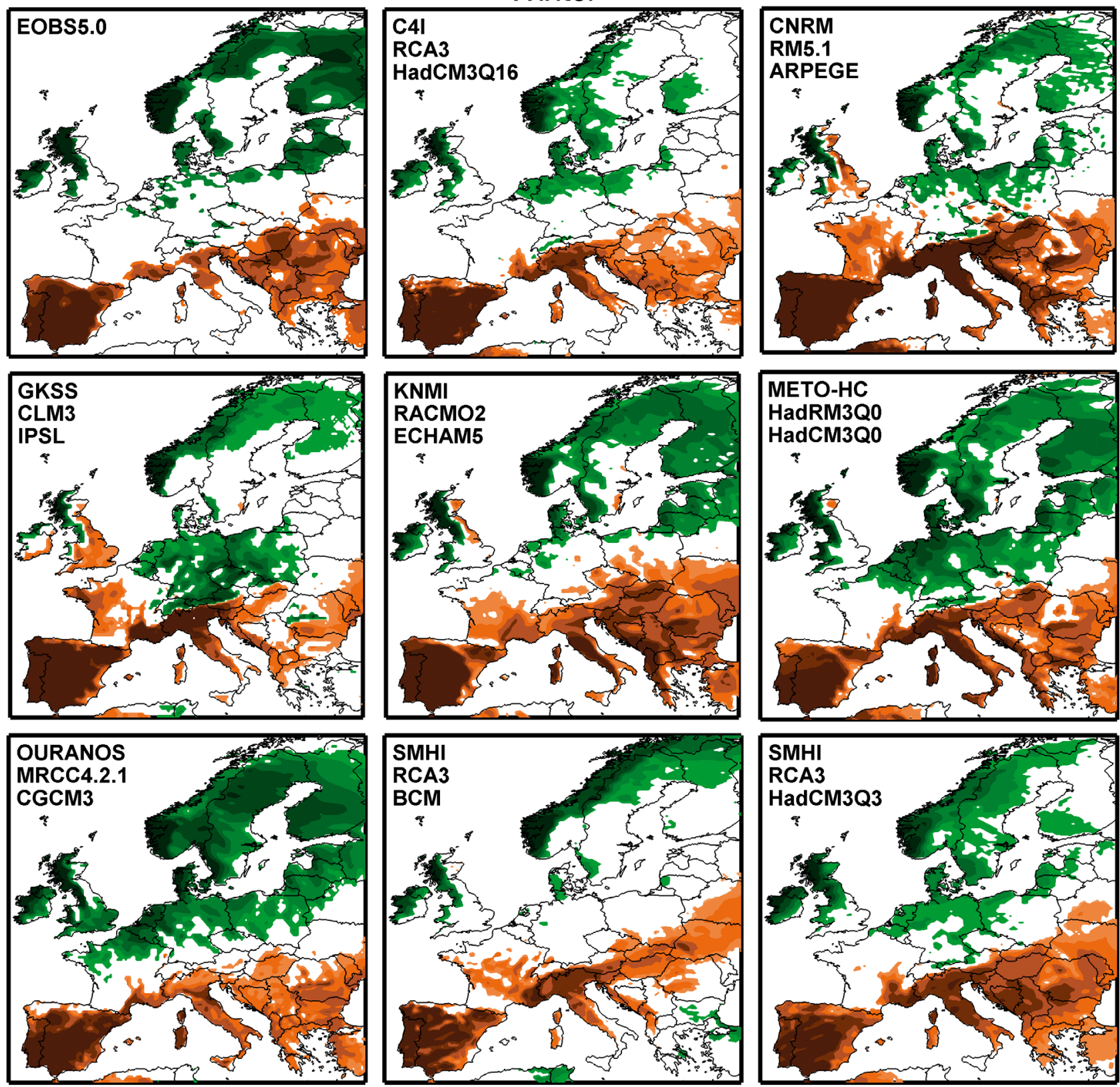

$-0.6$

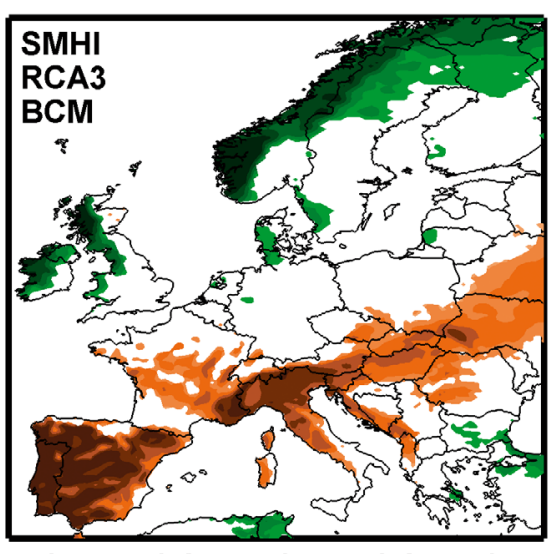

$\begin{array}{lllll}-0.4 & -0.2 & 0 & 0.2 & 0.4\end{array}$

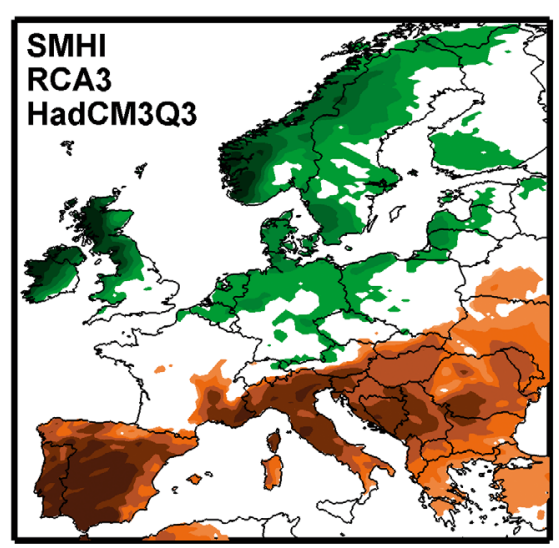

0.6

Correlation

Fig. 7. (Continued on next page.) Temporal correlation between seasonal mean NAOI and precipitation for 1961-2050. Other details as in Fig. 6, except here for precipitation

perature in parts of Western Europe, which is generally more marked in the RCMs than in E-OBS.

The results when the influence of the NAO on the temperature and precipitation series was removed for each region by regression, as explained above, are shown in Figs. 8 \& 9. If there were no effect of NAO, the respective change year would not change, and the points would fall on the diagonal. If the change year moves forward in time, the points end up above the diagonal. If the time of change moves earlier in time, the points will be below the diagonal.

Removing the influence of the NAO leads to earlier emergence of signals in the winter temperature for 

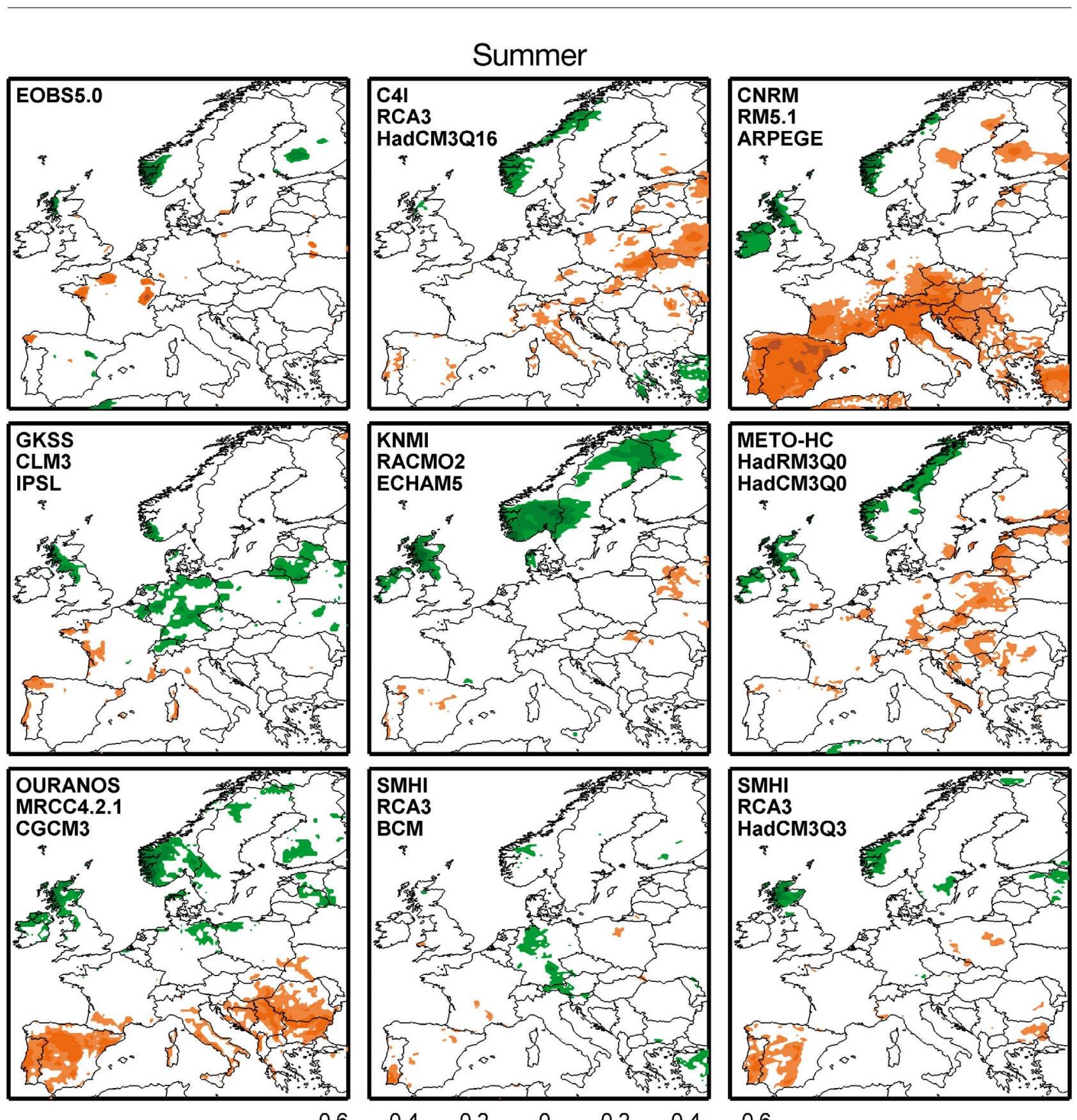

$-0.6$

$\begin{array}{lll}-0.4 & -0.2 & 0\end{array}$

0.2

0.4

0.6

\section{Correlation}

Fig. 7. (continued)

some models and regions (Fig. 8, Table 2). This is consistent with lowered variance due to removing the influence of the NAO, as the signals are easier to detect against a background with less variance. Relatively large shifts of about a decade are seen for a few models in the British Isles and the Mediterranean region. These are both regions with a relatively high degree of correlation between the temperature and
NAO index (Fig. 6). Detrending the NAOI does not generally affect the results (data not shown), which can be explained by the small time-trend in NAO here. For summer temperature, the NAO influence is small, and there are mostly minor changes (Fig. 8).

Also, for precipitation, there is an earlier emergence of signals when the NAO influence is removed in the models (Fig. 9). This is most pronounced in 


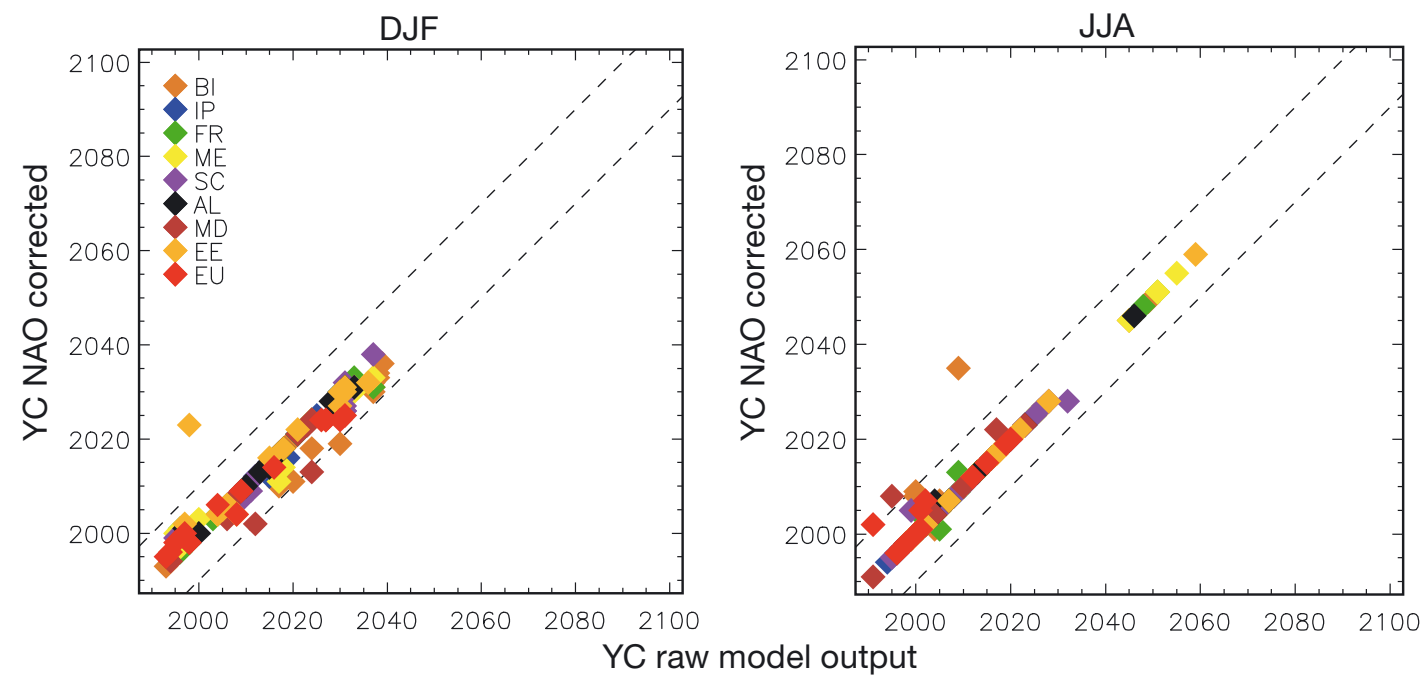

Fig. 8. Year of significant change (YC) in period-means of temperature with (horizontal axis) and without (vertical axis) the effect of the NAO for winter (left) and summer (right). The dashed lines indicate a shift in time $\pm 10 \mathrm{yr}$

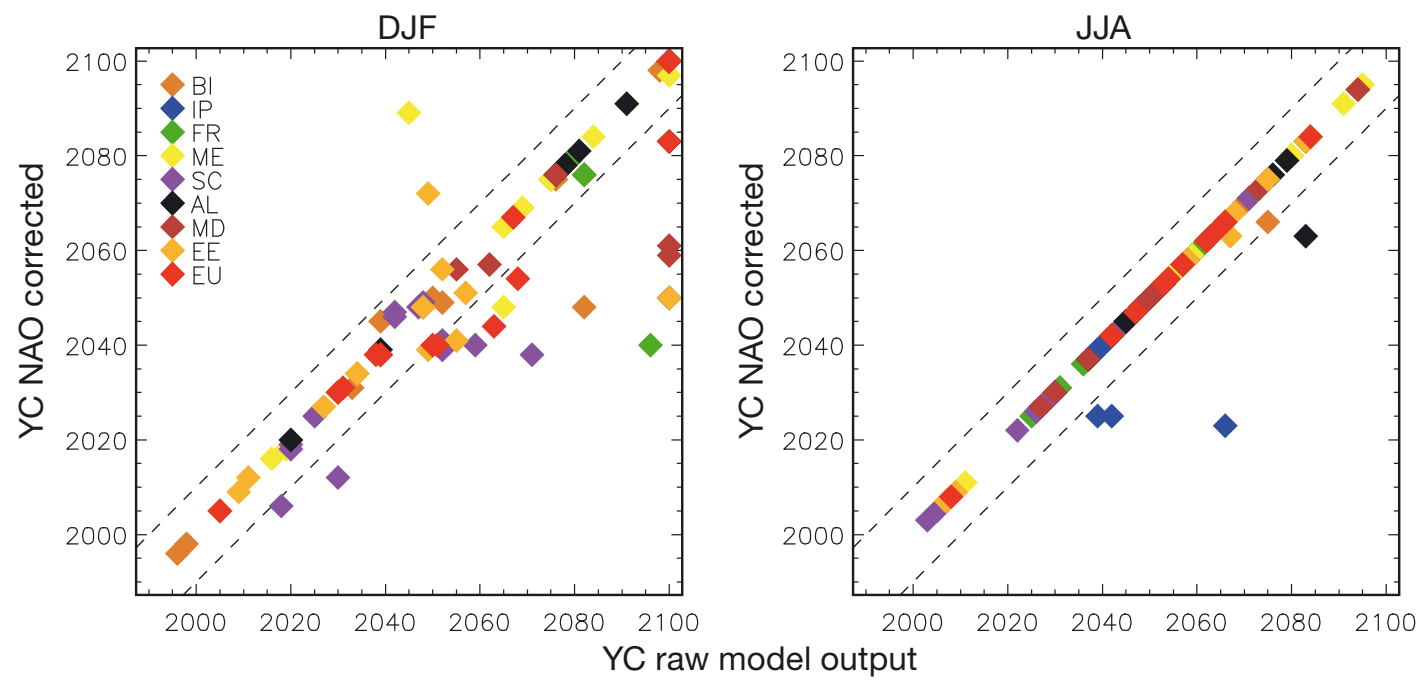

Fig. 9. Year of significant change (YC) in period-means for precipitation with (horizontal axis) and without (vertical axis) effect of the NAO for winter (left) and summer (right). The data points are for those different models for which a 'first year of change' was obtainable, i.e. models for which that year did not fall outside the data range in both raw model output and NAO corrected data. In some winter cases, a YC during the 21st century was only obtained in the NAO corrected data, these are marked to the right (at YC $=2100)$. The dashed lines indicate a shift in time $\pm 10 \mathrm{yr}$

winter, while it is only seen for a few cases in summer. Compared to temperature, we note that some models and regions now fall outside of the plotting ranges in both raw model output and NAO corrected data. Further, in some winter cases, a year of emergence lies within the 21st century only in the NAO corrected data; these are also included in the figure (at $\mathrm{YC}=2100$ on the horizontal axis) to better emphasize the role of the NAO influence. Table 2 shows that the median year of change emerges 1 to 2 decades earlier in some of the regions for winter and summer precipitation when NAO is accounted for, while in the other areas, there is no difference.

\section{DISCUSSION}

A clear temperature change signal emerges in most of the RCMs around 2020. For precipitation, the results are much more variable, which is at least partially explainable by the large natural variability of precipitation as well as the models' different patterns, and magnitudes of the projected changes (cf. Figs. 3 \& 4). In some parts of Europe, the projected precipitation changes are furthermore quite small, which is aligned with the larger-scale distribution of increases toward high latitudes and decreases in the sub-tropics (e.g. Christensen et al. 2007). 
Our results generally agree with those of Diffenbaugh et al. (2011), who, based on projections with 1 GCM and 1 RCM and for a baseline of 1970-1999, found that over much of the continental USA, regional temperature change signals appeared before 2020, with some sub-regional variation. They also compared their results to studies using CMIP3 GCMs. Also based on CMIP3 GCMs, Giorgi \& Bi (2009) searched for the ToE of sub-continental precipitation change signals. For Europe, their analysis included the winter half-year in Northern Europe and both half-years in the Mediterranean. For the former region, they found a signal prior to 2020, whereas for the latter, the signals came about in the 2030s in most cases. Their results are not directly comparable to ours because they use another baseline (1980-1999) and also because they include both inter-model spread and internal model multi-decadal variability in their estimate of the uncertainty against which the signal is evaluated.

Hawkins \& Sutton (2012) analysed the ToE of temperature change signals in CMIP3 GCMs and emphasised the uncertainty related to the simulated internal variability. Their comparison was for halfyears and with respect to 1986-2005. They found an earlier ToE for the boreal summer than the boreal winter for much of Europe. This is in broad agreement to the present results in our study (Table 2). Further, they found that the signals emerged earlier in Southern than in Northern Europe. This is broadly consistent with the results presented here, for which a change in temperature generally emerges earlier in Southern Europe compared to the Scandinavian region (Fig. 5). For precipitation, however, this is not the case as the emergence is among the earliest in the Scandinavian region in both winter and summer.

The choice of the baseline period has of course some influence on the results (Ruokolainen \& Räisänen 2007). In the studies mentioned above, somewhat different periods have been used. A later reference period reasonably pushes the clear signals forward in time compared to an earlier one. We also note that our definition of the year of change taken as the middle of the $30 \mathrm{yr}$ interval is arbitrary, and another definition, such as the end of the interval, would of course alter the actual year of change, with implications for comparison to other studies. Differences between the present results and those in the other studies are likely also related to the differences in the number of GCM simulations and perhaps to the higher degree of detail in RCMs. Nevertheless, the number of GCMs that underlie these RCM simulations, although several, is small. For temperature with an earlier emergence, we therefore compare the results based on 15 models presented above with the larger 21-member ensemble consisting of all models in Table 1. This larger ensemble, including simulations based on 2 additional GCMs, differs only slightly from the 15-model ensemble (data not shown). Only in Scandinavia in winter and in Eastern Europe in spring and summer do the median years of emergence differ by $>10$ yr between the 2 ensembles. The similarity between the 2 sets of data indicates that the 15-member ensemble is a relatively good representative of the larger 21-member ensemble, at least for temperature. In contrast, the ENSEMBLES RCM projections only cover part of the uncertainty range (van der Linden \& Mitchell 2009), implying that the uncertainty in our estimates probably appears smaller than if a larger number of GCMs had been used. However, we also emphasize here that model spread is not a sufficient measure of true uncertainty (Räisänen 2007).

Cimate aspects other than seasonal temperature and precipitation may have a different signal (change) to noise (internal variability) ratio. On a global scale, there are expectations of an early emergence of signals in temperature extremes (Zwiers et al. 2011). In some parts of Europe, depending on the season, the cold and warm extremes show larger projected changes than the corresponding seasonal means (Nikulin et al. 2011). At the same time, the interannual variability is high in Europe, and the emergence of a statistically significant change lags behind that of lower latitudes (e.g. Ruokolainen \& Räisänen 2009). Nevertheless, if the question were posed not as 'when can we expect to see significant changes in the seasonal means' but as 'when can we expect to see significant climate changes', additional indices and metrics would clearly need to be considered, depending on the application. Thus, our results should not be interpreted as showing the earliest possible emergence of regional-scale climate change from the 1961-1990 internal variability envelope. A different approach is to examine the probability that conditions will change across specific periods. Räisänen \& Alexandersson (2003), used CMIP2 (Meehl et al. 2000) GCMs to make a probabilistic forecast for the Swedish climate in the first decade of the 21st century, and suggested a $95 \%$ possibility of warmer annual means and an $87 \%$ possibility of wetter conditions compared to 1961-1990.

The assumption of which emission scenario to incorporate is probably less crucial for the first half of the century (cf. Giorgi \& Bi 2009), except for lower emission scenarios (Hawkins \& Sutton 2012). A fur- 
ther development of the study could be to consider RCM biases as diagnosed from model evaluation, and determine whether these biases could be invariant in terms of changing climate (cf. Buser et al. 2009, Lorenz \& Jacob 2010, Boberg \& Christensen 2012, van Haren et al. 2012). Another issue could be aerosols' regional-scale climate effects and their temporal evolution, given the expectations of decreasing aerosol or aerosol precursor emissions in Europe. RCMs that do not carry aerosol effects could thus deviate from those that do when aerosols change over time.

\section{SUMMARY AND CONCLUSIONS}

Regional temperature and precipitation time series were extracted from a number of RCM projections until the end of the 21st century. A means test was applied between sliding windows and the 1961-1990 reference period for each model and both variables for a number of European sub-regions and the whole of Europe. The first year when the temperature and precipitation, respectively, changed significantly (at the $99 \%$ level) was analysed.

The models' NAO was correlated against the models' temperature and precipitation. The overall modelled correlation patterns resembled those observed. The effect of the removal of the NAO influence from the temperature and precipitation fields was analysed to look for a possible masking effects of the NAO influence on the emergence of forced climate change signals in regional temperature and precipitation. NAO variability has some significance for the result. Removal of the NAO influence resulted in an earlier emergence of signals in winter temperature for some models and regions. This is also true for precipitation and again most pronounced in winter. Detrending the NAOI did not generally affect the results. Based on the results, it was concluded that regional-scale climate change signal in seasonal temperatures could be expected to emerge around 2020 in much of Europe, including sub-regional scales. The results also show that the models that show an early significant change in temperature are more in line with the observations than the ensemble mean. Whether these 'earliest' GCM-RCM combinations have more realistic climate sensitivity than the others or if this is a result of natural variability remains an open question. For precipitation, the results are much more variable, and in some areas, robust signals do not emerge by 2100 in the considered projections.
Acknowledgements. Part of this work was done in the IMPACT2C and ECLISE projects that receive funding from the European Union Seventh Framework Programme (FP7/2007-2013) under grant agreements 282746 and 265240 , respectively. Part of this work was done under the Swedish strategic research area ModElling the Regional and Global Earth system (MERGE). In addition, this study received financial support from the Danish Agency for Science, Technology and Innovation through the Centre for Regional Change in the Earth System (CRES; www.crescentre.dk) under contract no. DSF-EnMi 09-066868. The ENSEMBLES RCM data and E-OBS data used in this work was funded by the EU FP6 Integrated Project ENSEMBLES (contract no. 505539), whose support is gratefully acknowledged. Further, we acknowledge the data providers in the ECA\&D project. The Climate Analysis Section at NCAR, Boulder, $\mathrm{CO}$, is acknowledged for updating and providing data on the NAO index. Finally, we are grateful for the constructive comments on a previous version of the manuscript made by 3 anonymous reviewers.

\section{LITERATURE CITED}

Boberg F, Christensen JH (2012) Overestimation of Mediterranean summer temperature projections due to model deficiencies. Nature Clim Change 2:433-436

> Buser CM, Kunsch HR, Lüthi D, Wild M, Schär C (2009) Bayesian multi-model projection of climate: bias assumptions and interannual variability. Clim Dyn 33:849-868

Christensen JH, Christensen OB (2007) A summary of the PRUDENCE model projections of changes in European climate by the end of the century. Clim Change 81:7-30

Christensen JH, Hewitson B, Busuioc A, Chen A and others (2007) Regional climate projections. In: Solomon S, Qin D, Manning M, Chen Z and others (eds) Climate change 2007: the physical science basis. Contribution of Working Group I to the Fourth Assessment Report of the Intergovernmental Panel on Climate Change. Cambridge University Press, Cambridge, p 847-940

Collins M, Booth BBB, Bhaskaran B, Harris GR, Murphy JM, Sexton DMH, Webb MJ (2011) Climate model errors, feedbacks and forcings: a comparison of perturbed physics and multi-model ensembles. Clim Dyn 36: $1737-1766$

Déqué M, Rowell DP, Lüthi D, Giorgi F and others (2007) An intercomparison of regional climate simulations for Europe: assessing uncertainties in model projections. Clim Change 81(Vol 1, Suppl):53-70

> Déqué M, Somot S, Sanchez-Gomez E, Goodess CM, Jacob D, Lenderink G, Christensen OB (2012) The spread amongst ENSEMBLES regional scenarios: regional climate models, driving general circulation models and interannual variability. Clim Dyn 38:951-964

> Diffenbaugh NS, Ashfaq M, Scherer M (2011) Transient regional climate change: analysis of the summer climate response in a high-resolution, century-scale ensemble experiment over the continental United States. J Geophys Res 116:D24111, doi:10.1029/2011JD016458

Ebisuzaki W (1997) A method to estimate the statistical significance of a correlation when the data are serially correlated. J Clim 10:2147-2153

ENSEMBLES (2012) Regional climate model data base from the ENSEMBLES project. Available at http://ensemblesrt 3.dmi.dk/ (accessed 01 January 2012) 
Feser F, Rockel B, von Storch H, Winterfeldt J, Zahn M (2011) Regional climate models add value to global model data: a review and selected examples. Bull Am Meteorol Soc 92:1181-1192

Giorgi F, Bi X (2009) Time of emergence (TOE) of GHGforced precipitation change hot-spots. Geophys Res Lett 36:L06709, doi:10.1029/2009GL037593

Haugen JE, Iversen T (2008) Response in extremes of daily precipitation and wind from a downscaled multimodel ensemble of anthropogenic global climate change scenarios. Tellus 60A:411-426

Hawkins E, Sutton R (2009) The potential to narrow uncertainty in regional climate predictions. Bull Am Meteorol Soc 90:1095-1107

> Hawkins E, Sutton R (2012) Time of emergence of climate signals. Geophys Res Lett 39:L01702, doi:10.1029/2011 GL050087

Haylock MR, Hofstra N, Klein Tank AMG, Klok EJ, Jones PD, New M (2008) A European daily high-resolution gridded dataset of surface temperature and precipitation. J Geophys Res 113:D20119, doi:10.1029/2008JD 010201

- Hegerl G, Zwiers F (2011) Use of models in detection and attribution of climate change. WIREs Clim Change 2: 570-591

Hegerl GC, Zwiers FW, Braconnot P, Gillett NP and others (2007) Understanding and attributing climate change. In: Solomon S, Qin D, Manning M, Chen Z and others (eds) Climate change 2007: the physical science basis. Contribution of Working Group I to the Fourth Assessment Report of the Intergovernmental Panel on Climate Change. Cambridge University Press, Cambridge, p 663-746

> Hurrell JW (1995) Decadal trends in the North Atlantic Oscillation: regional temperatures and precipitation. Science 269:676-679

Joshi M, Hawkins E, Sutton R, Lowe J, Frame D (2011) Projections of when temperature change will exceed $2^{\circ} \mathrm{C}$ above pre-industrial levels. Nature Clim Change 1:407-412

Kendon E, Jones R, Kjellström E, Murphy J (2010) Using and designing GCM-RCM ensemble regional climate projections. J Clim 23:6485-6503

Kjellström E, Ruosteenoja K (2007) Present-day and future precipitation in the Baltic Sea region as simulated in a suite of regional climate models. Clim Change 81(Vol 1, Suppl):281-291

Kjellström E, Nikulin G, Hansson U, Strandberg G, Ullerstig A (2011) 21st century changes in the European climate: uncertainties derived from an ensemble of regional climate model simulations. Tellus 63A:24-40

Lorenz P, Jacob D (2010) Validation of temperature trends in the ENSEMBLES regional climate model runs driven by ERA40. Clim Res 44:167-177

Mahlstein I, Portmann RW, Daniel JS, Solomon S, Knutti R (2012) Perceptible changes in regional precipitation in a future climate. Geophys Res Lett 39:L05701, doi:10.1029/ 2011GL050738

Meehl GA, Boer GJ, Covey C, Latif M, Stouffer RJ (2000) The Coupled Model Intercomparison Project (CMIP). Bull Am Meteorol Soc 81:313-318

Meehl GA, Stocker TF, Collins WD, Friedlingstein P and

Editorial responsibility: Mauricio Lima,

Santiago, Chile others (2007) Global climate Projections. In: Solomon S, Qin D, Manning M, Chen Z and others (eds) Climate change 2007: the physical science basis. Contribution of Working Group I to the Fourth Assessment Report of the Intergovernmental Panel on Climate Change. Cambridge University Press, Cambridge, p 747-846

Nakićenović N, Swart R (eds) (2000) Special report on emissions scenarios. A Special Report of Working Group III of the Intergovernmental Panel on Climate Change. Cambridge University Press, Cambridge

NAO (2012) NAO index data provided by the Climate Analysis Section, NCAR, Boulder, USA, Hurrell (1995). Available at https://climatedataguide.ucar.edu/guidance/ hurrell-north-atlantic-oscillation-nao-index-stationbased (accessed 01 January 2012)

Nikulin G, Kjellström E, Hansson U, Jones C, Strandberg G, Ullerstig A (2011) Evaluation and future projections of temperature, precipitation and wind extremes over Europe in an ensemble of regional climate simulations. Tellus 63A:41-55

Pinto GJ, Raible CC (2012) Past and recent changes in the North Atlantic oscillation. WIREs Clim Change 3:79-90

Räisänen J (2007) How reliable are climate models? Tellus 59A:2-29

Räisänen J, Alexandersson H (2003) A probabilistic view on recent and near future climate change in Sweden. Tellus 55A:113-125

> Rummukainen M (2010) State-of-the-art with regional climate models. WIREs Clim Change 1:82-96

Ruokolainen L, Räisänen J (2007) Probabilistic forecasts of near-term climate change: sensitivity to adjustment of simulated variability and choice of baseline period. Tellus 59A:309-320

Ruokolainen L, Räisänen J (2009) How soon will climate records of the 20th century be broken according to climate model simulations? Tellus 61A:476-490

Sheffield J, Wood EF (2008) Projected changes in drought occurrence under future glocal warming from multimodel, multi-scenario, IPCC AR4 simluations. Clim Dyn 31:79-105

Stott PA, Gillett NP, Hegerl GC, Karoly DJ, Stone DA, Zhang X, Zwiers F (2010) Detection and attribution of climate change: a regional perspective. WIREs Clim Change 1: 192-211

- Thejll PA (2001) Decadal power in land air temperatures: Is it statistically significant? J Geophys Res 106:31693-31702

van der Linden P, Mitchell JFB (eds) (2009) ENSEMBLES: climate change and its impacts: summary of research and results from the ENSEMBLES project. Met Office Hadley Centre, Exeter

van Haren R, van Oldenborgh GJ, Lenderink G, Collins M, Hazeleger W (2012) SST and circulation trend biases cause an underestimation of European precipitation trends. Clim Dyn 40:1-20

van Oldenborgh GJ, Drijfhout S, van Ulden A, Haarsma R and others (2009) Western Europe is warming much faster than expected. Clim Past 5:1-12

> Zwiers FW, Zhang X, Feng Y (2011) Anthropogenic influence on long return period daily temperature extremes at regional scales. J Clim 24:881-892

Submitted: August 1, 2012; Accepted: November 27, 2012

Proofs received from author(s): February 26, 2013 